\title{
Laparoscopic approach in the treatment of large leiomyoma of the lower third of the esophagus
}

\author{
Vytautas Lipnickas ${ }^{1}$, Augustas Beiša ${ }^{1}$, Gabija Makūnaitè${ }^{2}$, Kęstutis Strupas ${ }^{1}$ \\ ${ }^{1}$ Center of Abdominal Surgery, Clinic of Gastroenterology, Nephrourology and Surgery, Institute of Clinical Medicine, \\ Faculty of Medicine, Vilnius University, Vilnius, Lithuania \\ ${ }^{2}$ Center of Abdominal Surgery, Faculty of Medicine, Vilnius University, Vilnius, Lithuania
}

Videosurgery Miniinv 2017; 12 (4): 437-442

DOI: https://doi.org/10.5114/wiitm.2017.72327

\begin{abstract}
Leiomyoma of the lower third of the esophagus is a relatively rare disorder but the most common benign tumor of the esophagus. We present a case of an involuted esophageal leiomyoma, $11 \mathrm{~cm}$ in size, treated by the laparoscopic approach. The preoperative computed tomogram visualized a mass $3 \times 1.5 \mathrm{~cm}$ in diameter in the lower esophagus without an eccentric lumen or compression of nearby organs. Resection of the tumor was indicated according to the patient's symptoms and to exclude malignancy. Laparoscopic enucleation of esophageal leiomyoma was performed. The overall operative time was $205 \mathrm{~min}$. The diagnosis of leiomyoma was established on histopathology and immunohistochemistry staining. The patient resumed the intake of a normal diet on the $5^{\text {th }}$ postoperative day and was discharged from hospital 8 days after the surgery. We have found this minimally invasive operation to be an effective and well-tolerated treatment option, determined by the experience of the surgeon.
\end{abstract}

Key words: minimally invasive surgery, enucleation, esophageal leiomyoma, giant leiomyoma.

\section{Introduction}

Benign tumors of the esophagus are rare lesions that constitute less than $1 \%$ of esophageal neoplasms, two thirds of them being leiomyomas [1-3]. Esophageal leiomyoma usually affects middle-aged patients and occurs twice as often in men as in women [2, 4]. The size of a lesion may not change for many years and cause no symptoms. However, some esophageal leiomyomas become large and show symptoms that are not specific for the disease, such as dysphagia or pain [5-8]. The optimal modality for diagnosis and treatment is controversial. Mostly leiomyomas are discovered incidentally during radiographic or endoscopic examinations or during autopsy [1]. The challenge of differentiating the esophageal leiomyoma from foreign oppressed disease of the esophagus, malignant esophageal tumors such as leiomyosarcoma and other benign tumors is a part of the diagnostic process. Computed tomography scans and esophagoscopy are also used for the diagnosis of esophageal leiomyoma. On endoscopic ultrasound, leiomyoma can easily be differentiated from lipoma, cyst, or hemangioma in the esophageal wall $[8,9]$. Preoperative biopsy of the tumor is a debated issue, because inconclusive biopsy is often due to inadequate material [10]. Giant esophageal leiomyoma is traditionally treated by open thoracotomy [11]. Recently, some centers have been implementing minimally invasive surgery for the treatment of giant esophageal leiomyoma, including resection or enucleation of esophageal leiomyoma by thoracoscopy, laparoscopy or Da Vinci robot-assisted thoracoscopy [12-15].

\section{Address for correspondence}

Augustas Beiša, Center of Abdominal Surgery, Clinic of Gastroenterology, Nephrourology and Surgery, Institute of Clinical Medicine,

Faculty of Medicine, Vilnius University, Santariskiu 2, LT-08661 Vilnius, Lithuania, phone: +37 061490532, e-mail: augustas.beisa@santa.lt 
We report the case of a laparoscopic approach to a large esophageal leiomyoma.

\section{Case report}

A 41-year-old man presented to our hospital with discomfort and progressive epigastric pain that he had been suffering after eating for 5 years. Upper gastrointestinal endoscopy, which was performed 5 years ago, revealed a large submucosal growth in the lower esophagus 38-41 cm from the incisor teeth, with normal overlying mucosa. Endosonos-

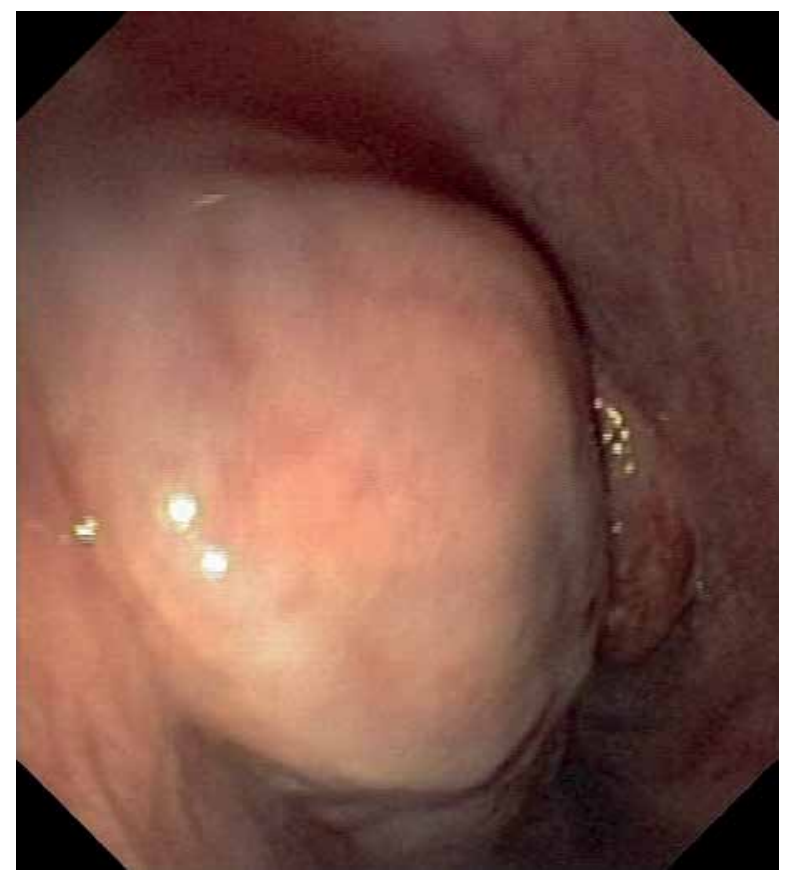

Photo 1. Preoperative endoscopy

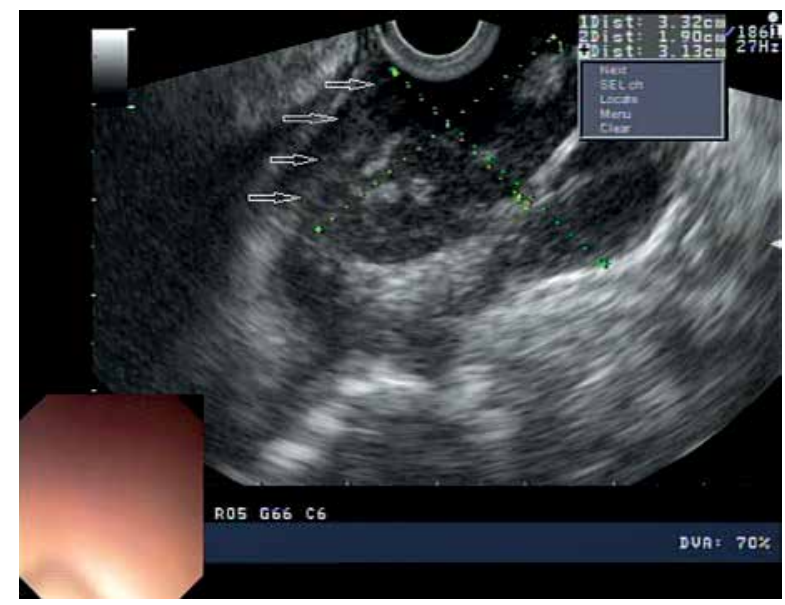

Photo 2. Preoperative endosonoscopy copy showed a $3.0 \times 1.5 \mathrm{~cm}$, heteroechoic lesion with hyperechoic insertions; possible malignancy was suspected (Photos 1 and 2). Ultrasound-guided fine-needle aspiration biopsy was performed, but not enough material for histopathological diagnosis was withdrawn. The preoperative study included contrast-enhanced computed tomography (CT) of the chest to exclude any neoplastic strictures. It confirmed the diagnosis of a well-circumscribed soft tissue opacity with homogeneous density located on the left and dorsal sides in the lower third of esophagus, without para-esophageal lymphadenopathy, suggestive of leiomyoma of the esophagus. Growth over the organ borders or infiltration in neighboring structures was not detected. Surgical resection of the large leiomyoma was recommended, but the patient refused to have an operation. A few months before this hospitalization the patient started to complain of dysphagia and discomfort from solids. Endoscopy and CT of the chest were performed repeatedly to measure the dynamics of the tumor size and exclude malignancy. Increase of the tumor size was not observed; it remained almost the same at $4.1 \times 2.3 \times 4.0 \mathrm{~cm}$ in diameter in the lower esophagus (Photo 3 ). It suggested the diagnosis of benign esophageal neoplasm. Surgery was indicated due to the manifestation of the patient's symptoms and to exclude a malignant process conclusively. Laparoscopic extirpation of submucosal tumor of the esophagus was planned. We decided to use a laparoscopic approach instead of thoracoscopic, because the tumor was located at the lower third of the esophagus.

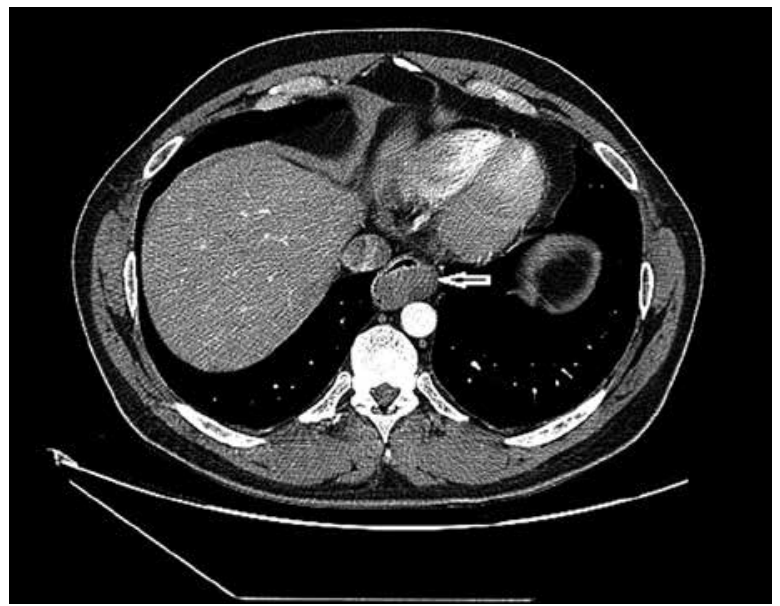

Photo 3. Preoperative spiral computed tomographic (CT) scan 
Informed patient consent was obtained before the procedure. The patient was brought under general anesthesia with endotracheal intubation; surgery was performed by the laparoscopic approach. After pneumoperitoneum formation, the camera port for video laparoscope $(10 \mathrm{~mm})$ was placed. Under the control of the laparoscope, four trocars were introduced: two $10 \mathrm{~mm}$ trocars on the left side of the abdomen and two trocars (10 $\mathrm{mm}$ and $5 \mathrm{~mm}$ ) on the right side of the abdomen were inserted (Figure 1). After the esophagogastric junction was exposed, mobilization of the lower part of the esophagus was performed. When accurate positioning of the tumor was achieved, a $5 \mathrm{~cm}$ long myotomy was made. A well-defined, circular, involute whitish solid tumor located on the left and dorsal sides in the lower third of the esophagus was revealed (Photo 4). During dissection of the tumor a 7-8 mm lesion of esophageal mucosa was performed. After preparation of the tumor was completed, the defect of the esophageal wall was sewn with vicryl 3/0 continuous stitches and intraoperative esophagogastroscopy was performed. An intraoperative air leak test was performed, in order to evaluate the integrity of the mucosa. The esophageal muscular layer was sutured using vicryl 3/0 interrupted stitches (Photo 5). The resected tumor was removed in a retrieval bag through the $10 \mathrm{~mm}$ port on the left side of the abdomen, which was enlarged for its delivery. No abdominal cavity drain was placed. The trocar wounds were sutured. The solid straightened tumor was approximately $11 \mathrm{~cm} \times 3 \mathrm{~cm} \times 3 \mathrm{~cm}$ in size (Photo 6). The difference between the CT measured tumor size and its real size was so big because of its circular configuration. The overall operative time was $205 \mathrm{~min}$.

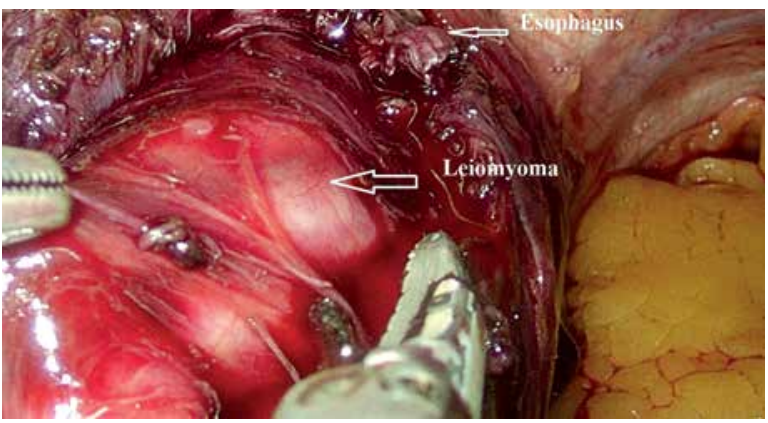

Photo 4. Perioperative videoendoscopic image. The view during dissection of the esophageal leiomyoma

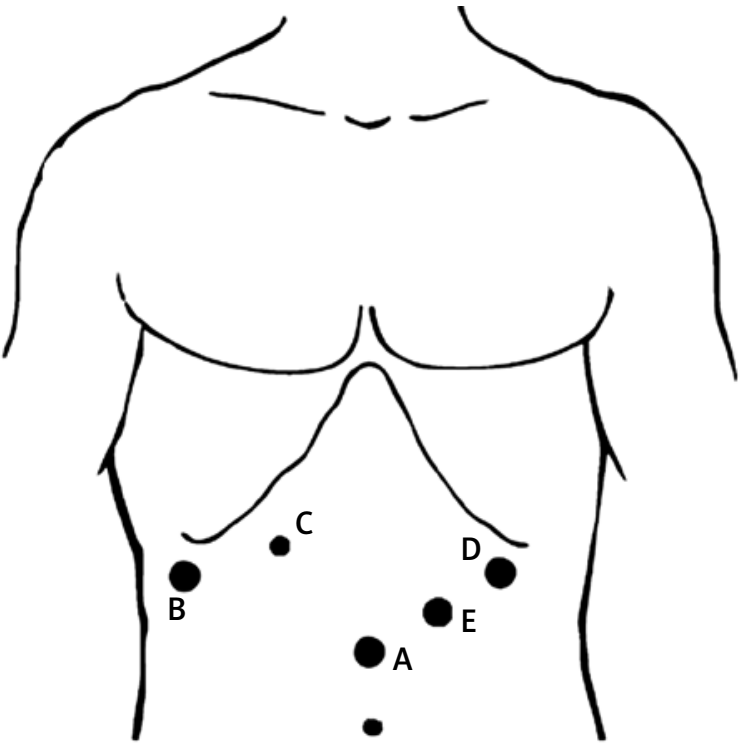

Figure 1. Positioning of trocars. $A-10 \mathrm{~mm}$, the camera port, $B-10 \mathrm{~mm}, \mathrm{C}-5 \mathrm{~mm}, \mathrm{D}-10 \mathrm{~mm}$, $\mathrm{E}-10 \mathrm{~mm}$

The operation and early postoperative period showed no major complications. The patient started a fluid diet on the $1^{\text {st }}$ postoperative day and resumed intake of a normal diet on the $5^{\text {th }}$ postoperative day. It was tolerated well, with no complaints of pain or dysphagia. No postoperative wound infection or esophageal leakage was observed. On the $7^{\text {th }}$ postoperative day we performed a radiological examination of the upper digestive tract with contrast to exclude postoperative pneumothorax or hydrothorax. The patient was discharged from hospital 8 days after the surgery. Histopathologic examination revealed a tumor measuring $11 \mathrm{~cm} \times 3 \mathrm{~cm} \times 3 \mathrm{~cm}$, and there was poor mitotic activity $(<1 \%)$, and no cellu-

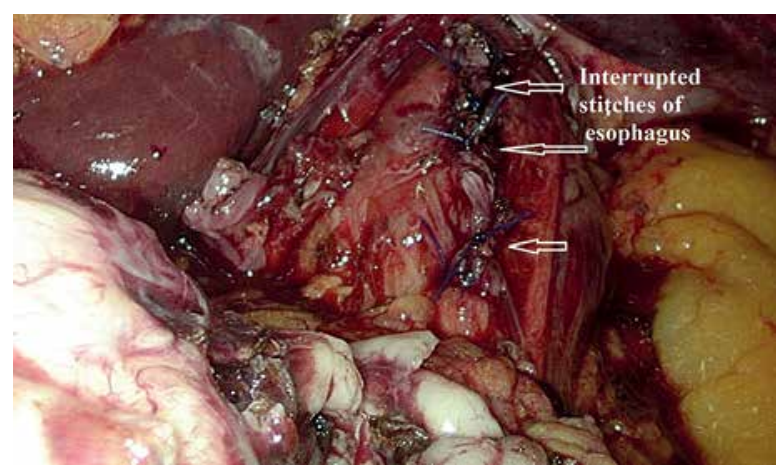

Photo 5. Perioperative videoendoscopic image. The view after esophageal mucosa was sutured 

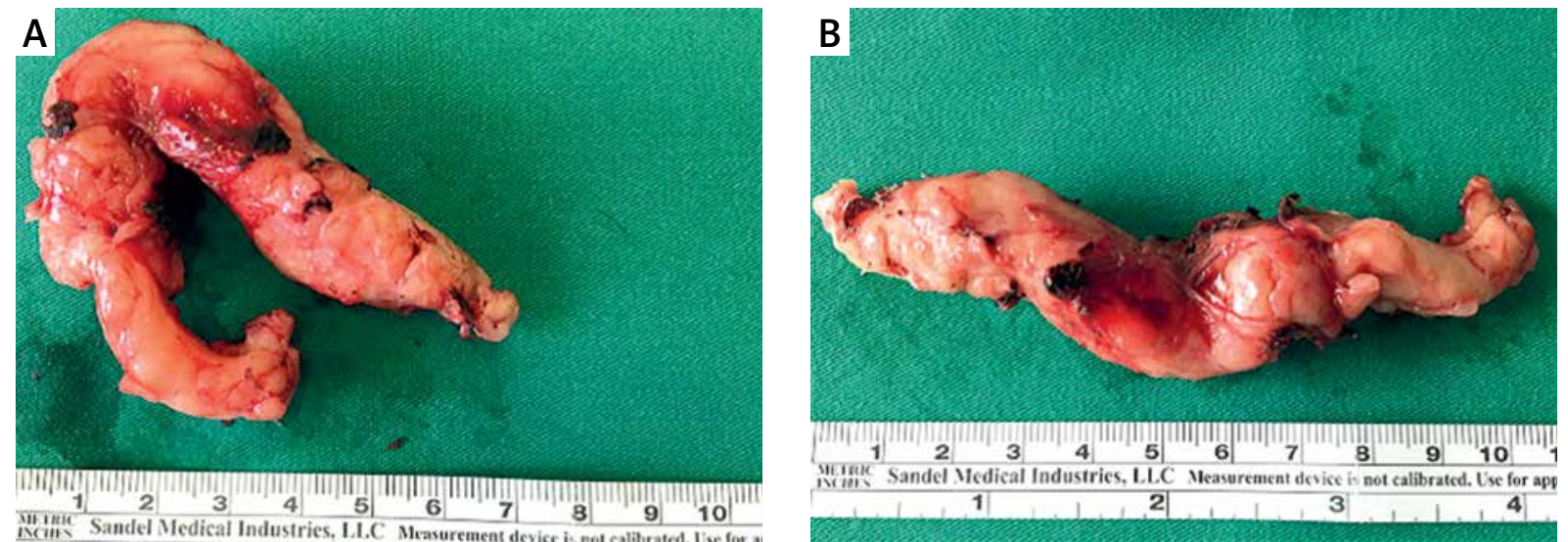

Photo 6. Excised specimen of esophageal leiomyoma after operation. A - circular, involute whitish solid tumor, $\mathbf{B}$ - view of straightened tumor

lar atypia or areas of necrosis. Currently, half a year after the surgery, he is asymptomatic, without any evidence of recurrence upon imaging studies.

The immunohistochemical staining was positive for smooth muscle actin (SMA) and desmin and negative for C-kit, DOG1 and DSO0. The diagnosis of gastrointestinal stromal (GIST) can be established by the presence of C-kit mutations and positivity for CD117 and CD34. Contrarily, leiomyomas are CD34, CD117 and C-kit negative, but are positive for desmin and SMA, in contrast to GISTs, which are usually negative [15]. Overall, morphology was consistent with a large leiomyoma.

\section{Discussion}

Benign tumors of the esophagus are rare lesions that constitute less than $1 \%$ of esophageal neoplasms. Nearly two thirds of benign esophageal tumors are leiomyomas; the others are mostly cysts $(20 \%)$, polyps $(5 \%)$, gastrointestinal stromal tumors $(<5 \%)$ and less than $1 \%$ are lipomas $[1-3,16,17]$.

Sussius was the first to use the phrase benign esophageal tumor to describe the condition in 1559. The tumor was discovered on autopsy, located in the distal esophagus, and was cited as a leiomyoma, although histologic confirmation was lacking. In 1932 Sauerbach performed a partial esophagectomy with esophagogastrostomy for a leiomyoma, and it was the first successful surgical treatment of a benign esophageal tumor. One year later, the first open enucleation of a leiomyoma was performed by Oshawa [18].

Esophageal leiomyoma usually affects patients between 20 and 50 years of age, with a male to fe- male ratio of $2: 1$ and a propensity to develop in the lower two-thirds of the esophagus [2, 4]. Esophageal leiomyoma derives from the muscularis mucosae or muscularis propria layer of the esophagus, and represents hyperproliferation of interlacing bundles of smooth muscle cells that are well demarcated by adjacent tissue or by a smooth connective tissue capsule $[19,20]$. The size of the lesion may not change for many years. Most patients are asymptomatic. However, about $5 \%$ of esophageal leiomyomas become giant (diameter of tumor larger than $10 \mathrm{~cm}$ ) gradually and show symptoms, such as dysphagia and pain, caused by compression of the tumor, obstruction of the esophagus or dysfunction of the cardia, that are not specific for the disease [5-8, 15]. Giant esophageal leiomyomas can grow toward the outside of the esophageal lumen, so dysphagia and the severity of other symptoms are not always proportionate to the size of the tumor [8].

The optimal modality for diagnosis and treatment is controversial. The majority of leiomyomas are discovered incidentally during radiographic or endoscopic examinations performed for evaluation of dysphagia or during autopsy [1]. The sensitivity and specificity of a plain radiograph is low, and the mass must reach a significant size to become apparent [21]. Esophagography is most likely the best initial test to obtain in the evaluation of a symptomatic patient. The view of a smooth filling defect in the esophageal lumen without a mucosal abnormality is typical for benign esophageal tumors [8, 22]. Differential diagnoses include foreign body oppression of the esophagus, malignant esophageal tumors such as leiomyosarcoma and other benign tumors. 
Computed tomography scans of the chest in most cases show a mass originating from the esophagus without mediastinal lymphadenopathy. It is helpful to evaluate the extra-esophageal tumors and to exclude other mediastinal masses, but in giant leiomyoma, the tumor usually grows toward the outside of the esophageal lumen and forms a soft tissue shadow in the mediastinum, so it can be misdiagnosed as a mediastinal mass [8, 23]. Esophagoscopy is also used for the diagnosis of esophageal leiomyoma, but it only shows submucosal lesions. On endoscopic ultrasound, leiomyoma is presented as a homogeneous and hypoechoic lesion with clear margins, surrounded by a hyperechoic area, which can easily be differentiated from a lipoma, cyst, or hemangioma in the esophageal wall [8, 9]. Preoperative biopsy of the tumor is a debated issue, because in many cases biopsy cannot provide enough material to establish an accurate histopathological diagnosis [10, 17].

For the optimal treatment of esophageal leiomyoma it is important to consider many factors: tumor size, location, the patient's symptoms and general condition. The increased tumor size or size greater than $4 \mathrm{~cm}$, symptoms, mucosal ulceration or suspicious malignancy are surgical indications of these tumors' treatment $[23,24]$. In this case surgery was indicated due to the manifestation of the patient's symptoms, the size of the tumor and to exclude a malignant process. Regular follow-up with barium swallow and endoscopy are recommended for asymptomatic patients with lesions smaller than $5 \mathrm{~cm}$, because of a rare malignant transformation in leiomyomas $[24,25]$. Giant esophageal leiomyoma is traditionally treated by open thoracotomy [11]. Recently, some centers have been implementing minimally invasive surgery for the treatment of giant esophageal leiomyoma, including resection or enucleation of esophageal leiomyoma by thoracoscopy, laparoscopy or Da Vinci robot-assisted thoracoscopy [12-15]. Traditional surgical treatment of giant leiomyoma by open thoracotomy can cause a serious intraoperative trauma and negatively affect postoperative respiratory function. In addition, a worse prognosis is related to the risk of anastomotic leak and mediastinitis [11, 26]. However, an open approach should be considered for larger tumors or when technical difficulty is encountered [27]. Therefore, the giant size of a tumor is not an absolute contraindication for a minimally invasive approach any longer; the experience of the surgeon is more important in determining the way of operation. Minimally invasive surgery has the advantages of precision, flexibility and control and the surgeon has better conditions to preserve the esophageal mucosa. This is important, because laceration of the esophageal mucosa is the most common intraoperative and postoperative complication associated with enucleation of esophageal leiomyoma [11, 28]. The lacerated mucosa sites should immediately be repaired by suturing and the integrity of the esophageal mucosa should be confirmed with gastroscopy [11]. Furthermore, minimally invasive surgery is associated with minimal postoperative complications, shorter length of hospital stay and less pain, and it also brings better cosmetic results [29]. The choice of minimally invasive approaches for leiomyomas in the upper two-thirds of the esophagus is undoubtedly through thoracoscopic surgery, but either laparoscopic or thoracoscopic approaches can be used for those tumors in the lower third of the esophagus [30]. However, for very distal esophageal or proximal gastric lesions thoracoscopic enucleation is more challenging given the location of the tumor. Furthermore, indications for thoracoscopic or laparoscopic approaches depend on the experience of the surgeon. Therefore, laparoscopic extirpation of the tumor of the distal esophagus was performed in this case.

To sum up, minimally invasive treatment of large benign tumors of the esophageal wall is considered to be the method of choice. Despite the fact that the laparoscopic approach to large esophageal leiomyoma is challenging for the surgeon, the decreased postoperative complication rate, shorter hospitalization time and reduced postoperative pain are factors which support the choice of this method. However, more cases need to be gathered for further statistical analysis to prove the benefits of minimally invasive surgery in the treatment of giant esophageal leiomyoma and compare it with open surgery.

\section{Conclusions}

A large, $11 \mathrm{~cm}$ long, esophageal leiomyoma can be successfully enucleated through the laparoscopic approach. We have found this minimally invasive operation to be an effective and well-tolerated treatment option, determined by the experience of the surgeon. 


\section{Conflict of interest}

\section{The authors declare no conflict of interest.}

\section{References}

1. Jiang W, Rice TW, Goldblum JR. Esophageal leiomyoma: experience from a single institution. Dis Esophagus 2013; 26: 167-74.

2. Giacomo TD, Bruschini P, Arcieri S, et al. Partial oesophagectomy for giant leiomyoma of the oesophagus: report of 7 cases. Eur J Cardiothorac Surg 2014; 47: 143-5.

3. Shin S, Choi YS, Shim YM, et al. Enucleation of esophageal submucosal tumors: a single institution's experience. Ann Thorac Surg 2014; 97: 454-9.

4. Lee LS, Singhal S, Brinster CJ, et al. Current management of esophageal leiomyoma. J Am Coll Surg 2004; 198: 136-46.

5. Cheng BC, Chang S, Mao ZF, et al. Surgical treatment of giant esophageal leiomyoma. World J Gastroenterol 2005; 11: 4258-60.

6. Peters JH, DeMeester TR. Esophagus and diaphragmatic hernia. In: Schwartz's Principles of Surgery. Brunicardi FC, Andersen KD, Billiar RT, et al. (eds). McGraw-Hill, New York, NY, USA 2005; 906.

7. Guo J, Liu Z, Sun S, et al. Ligation-assisted endoscopic enucleation for treatment of esophageal subepithelial lesions originating from the muscularis propria: a preliminary study. Dis Esophagus 2015; 28: 312-7.

8. Xuefei S, Jiabang W, Guotao Y. Surgical treatment of esophageal leiomyoma larger than $5 \mathrm{~cm}$ in diameter: a case report and review of the literature. J Thorac Dis 2012; 4: 323-6.

9. Xu GQ, Zhang BL, Li YM, et al. Diagnostic value of endoscopic ultrasonography for gastrointestinal leiomyoma. World J Gastroenterol 2003; 9: 2088-91.

10. Punpale A, Rangole A, Bhambhani N, et al. Leiomyoma of esophagus. Ann Thorac Cardiovasc Surg 2007; 13: 78-81.

11. Hu X, Lee H. Complete thoracoscopic enucleation of giant leiomyoma of the esophagus: a case report and review of the literature. J Cardiothorac Surg 2014; 9: 34.

12. Boone J, Draaisma WA, Schipper ME, et al. Robot-assisted thoracoscopic esophagectomy for a giant upper esophageal leiomyoma. Dis Esophagus 2008; 21: 90-3.

13. Iscan Y, Tunca F, Senyurek YG, et al. Thoracoscopic enucleation of a giant leiomyoma of the esophagus. Surg Laparosc Endosc Percutan Tech 2013; 23: 32-4.

14. Compean SD, Gaur P, Kim MP. Robot assisted thoracoscopic resection of giant esophageal leiomyoma. Int J Surg Case Rep 2014; 5: 1132-4.

15. Gupta V, Sinha SK, Vaiphei K, et al. Esophageal resection for giant leiomyoma. J Cancer Res Ther 2015; 11: 651.

16. Yekeler E, Yazicioglu A, Subasi M, et al. Giant esophageal lipoma as an uncommon cause of diverticula. Case Rep Gastroenterol 2016; 10: 446-51.

17. Neoral C, Aujeský R, Skarda J, et al. Thoracoscopic treatment of benign esophageal tumors. Videosurgery Miniinv 2012; 7 : 294-8.

18. Watson RR, O'Connor TM, Weisel W. Solid benign tumors of the esophagus. Ann Thorac Surg 1967; 4: 80-91.
19. Massari M, Lattuada E, Zappa MA, et al. Evaluation of leiomyoma of the esophagus with endoscopic ultrasonography. Hepatogastroenterology 1997; 44: 727-31.

20. Se-Joon L, Yong-Han P, Dong-Ki L, et al. The diagnostic value of Endoprobe for small esophageal leiomyomas derived from the muscularis mucosae. Yonsei Med J 2005; 46: 61-5.

21. Storey CF, Adams WC. Leiomyoma of the esophagus: a report of four cases and review of the surgical literature. Am J Surg 1956; 91: 3-23.

22. Levine MS. Benign tumors of the esophagus: radiologic evaluation. Semin Thorac Cardiovasc Surg 2003; 15: 9-19.

23. Lee LS, Singhal S, Brinster CJ, et al. Current management of esophageal leiomyoma. J Am Coll Surg 2004; 198: 136-46.

24. Priego P, Lobo E, Alonso N, et al. Surgical treatment of esophageal leiomyoma: an analysis of our experience. Rev Esp Enferm Dig 2006; 98: 350-8.

25. Punpale A, Rangole A, Bhambhani N, et al. Leiomyoma of esophagus. Ann Thorac Cardiovasc Surg 2007; 13: 78-81.

26. Samphire J, Nafteux P, Luketich J. Minimally invasive techniques for resection of benign esophageal tumors. Semin Thorac Cardiovasc Surg 2003; 15: 35-43.

27. Kent M, d'Amato T, Nordman C, et al. Minimally invasive resection of benign esophageal tumors. J Thorac Cardiovasc Surg 2007; 134: 176-81.

28. Saleh WN, Bamosa A, Al-Mutairi H, et al. Thoracoscopic enucleation of esophageal leiomyoma in patient with MEN I syndrome. Ann Thorac Med 2010; 5: 47-9.

29. Chen X, Xi Y, Wang H, et al. Minimally invasive surgery for giant esophageal leiomyoma: a case report and review of the literatures. J Thorac Dis 2017; 9: E26-31.

30. Luh SP, Hou SM, Fang CH, et al. Video-thoracoscopic enucleation of esophageal leiomyoma. World J Surg Oncol 2012; 10: 52 .

Received: 27.07.2017, accepted: 6.10.2017. 